\title{
Direct Conversion Technology
}

\section{Annual Summary Report CY 1991}

Prepared by:

Paul F. Massier

and by

L. H. Back, M. A. Ryan and G. Fabris

Jet Propulsion Laboratory

California Institute of Technology

Report Period: January 1, 1991 to December 31, 1991

January 7,1992

Sponsored by

Advanced Industrial Concepts Division

Office of Industrial Technology

U.S. Department of Energy

Washington, D.C. 20585

Through an agreement with

National Aeronautics and

Space Administration

by

Jet Propulsion Laboratory

California Institute of Technology

Pasadena, Califomia 


\section{DISCLAIMER}

This report was prepared as an account of work sponsored by an agency of the United States Government. Neither the United States Government nor any agency Thereof, nor any of their employees, makes any warranty, express or implied, or assumes any legal liability or responsibility for the accuracy, completeness, or usefulness of any information, apparatus, product, or process disclosed, or represents that its use would not infringe privately owned rights. Reference herein to any specific commercial product, process, or service by trade name, trademark, manufacturer, or otherwise does not necessarily constitute or imply its endorsement, recommendation, or favoring by the United States Government or any agency thereof. The views and opinions of authors expressed herein do not necessarily state or reflect those of the United States Government or any agency thereof. 


\section{DISCLAIMER}

Portions of this document may be illegible in electronic image products. Images are produced from the best available original document. 
Prepared by the Jet Propulsion Laboratory, California Institute of Technology, for the U.S. Department of Energy through an agreement with the National Aeronautics and Space Administration.

This report was prepared as an account of work sponsored by an agency of the United States Government. Neither the United States Government nor any agency thereof, nor any of their employees, makes any warranty, express or implied, or assumes any legal liability or responsibility for the accuracy, completeness, or usefulness of any information, apparatus, product, or process disclosed, or represents that its use would not infringe privately owned rights.

Reference therein to any specific commercial product, process, or service by trade name, trademark, manufacturer, or otherwise, does not necessarily constitute or imply its endorsement, recommendation, or favoring by the United States Government or any agency thereof. The views and opinions of authors expressed herein do not necessarily state or reflect those of the United States Government or any agency thereof.

The work reported herein was performed through NASA Task RE-152, Amendment 308, and was sponsored by the U.S. Department of Energy under IAA DE-AI0186CE90237. 


\section{TABLE OF CONTENTS}

SUMMARY

A. INTRODUCTION ........................... 6

B. OBJECTIVES $\ldots \ldots \ldots \ldots \ldots \ldots \ldots \ldots \ldots \ldots \ldots \ldots \ldots \ldots \ldots$

C. RESEARCH ACTIVTTIES $\ldots \ldots \ldots \ldots \ldots \ldots \ldots \ldots \ldots \ldots \ldots \ldots \ldots$

1. Alkali Metal Thermal-to-Electric Converter (AMTEC) $\ldots \ldots \ldots \ldots \ldots$

a. Thermal Analysis of an AMTEC Cell ..............

b. Electrode Life and Performance Studies and Modeling . . . . . 10

c. Alternative AMTEC Systems $\ldots \ldots \ldots \ldots \ldots \ldots \ldots$

2. TWO-PHASE LIQUID-METAL MHD ELECTRICAL GENERATOR (LMMHD) ............................ 12

a. Computer Prediction Code $\ldots \ldots \ldots \ldots \ldots \ldots \ldots \ldots$

b. Liquid Metal MHD Blowdown Experimental Set-up . . . . . 15

c. LMMHD Generator $\ldots \ldots \ldots \ldots \ldots \ldots \ldots \ldots \ldots$

d. $\quad$ Test Facility $\ldots \ldots \ldots \ldots \ldots \ldots \ldots \ldots \ldots \ldots$

D. REFERENCES $\ldots \ldots \ldots \ldots \ldots \ldots \ldots \ldots \ldots \ldots \ldots \ldots \ldots \ldots \ldots \ldots \ldots$

E. PUBLICATIONS AND PRESENTATIONS $\ldots \ldots \ldots \ldots \ldots \ldots \ldots \ldots$

Appendix A. Papers Discussing AMTEC Cell and Electrode Performance, including Thermal Considerations ................. A-1

Appendix B. Thermal Modeling of an AMTEC Cell $\ldots \ldots \ldots \ldots \ldots \ldots \ldots \ldots$

Appendix C. Other AMTEC Presentations and Publications during $1991 \ldots \ldots$

Appendix D. Prediction of Performance of Two-Phase Flow Nozzle and Liquid Metal Magnetohydrodynamic (LMMHD) Generator for No Slip Condition . . . . . . . . . . . . . . . . D-1 


\section{SUMMARY}

The overall objective of the Direct Conversion Technology task is to develop an experimentally verified technology base for promising direct conversion systems that have potential application for energy conservation in the end-use sectors.

This report contains progress of research on the Alkali Metal Thermal-to-Electric Converter (AMTEC) and on the Two-Phase Liquid-Metal MHD Electrical Generator (LMMHD) for the period January 1, 1991 through December 31, 1991. Research on AMTEC and on LMMHD was initiated during October 1987. Reports prepared on previous occasions (Refs. 1-5) contain descriptive and performance discussions of the following direct conversion concepts: thermoelectric, pyroelectric, thermionic, thermophotovoltaic, thermoacoustic, thermomagnetic, thermoelastic (Nitionol heat engine); and also, more complete descriptive discussions of AMTEC and LMMHD systems.

Research on the Alkali Metal Thermal-to-Electric Converter (AMTEC) in 1991 has focussed on demonstration of efficiencies greater than $10 \%$ for a full tube, $120 \mathrm{~cm}^{2}$ electrode, AMTEC experiment in the Recirculating Test Cell (RTC), on optimization of electrode materials and current collection from the electrodes, and on demonstration of electrode stability and performance in long term, high temperature tests in the Vapor Exposure Test Cell (VETC). Three RTC experiments have been run since January, 1991. The first was operated at $1000-1150 \mathrm{~K}$ with a rhodium-tungsten electrode for 209 hours, and was used to test increase of efficiency by decrease of thermal losses at the condenser 
surface, power production, sodium recirculation with the electromagnetic pump, and electrode performance. In the second, an efficiency of $11.3 \%$ was measured in the RTC with a molybdenum electrode, in dynamic operation. An efficiency of $7.4 \%$ was measured on the same experiment at constant current. The third RTC experiment used a molybdenum electrode and a modified heat shield and operated for 850 hours. This experiment was run primarily to test the modified heat shield design; an efficiency of $8.6 \%$ was measured under load on this test.

Electrode performance modelling and elucidation of processes occurring at the AMTEC electrode, specifically sodium transport, have also been goals of AMTEC research this year.

Work which was specifically funded under the DOE-AICD program is thermal characterization of the RTC, including determination of the emissivity of RhW electrodes and of the condenser, and improvement in the condenser and/or heat shield in the RTC. Use of a heat shield in RTC tests this year resulted in significantly lower radiative heat loss at the condenser. The emissivity of $\mathrm{RhW}$ thin films was measured, and a cell for measuring operating temperatures in an AMTEC experiment has been designed and is being built.

Work which is funded by other sponsors involves studies of electrode life and performance, and cell efficiency. These studies include investigations of electrode materials and current collection, braze seals, and high efficiency continuous operation tests. There 
is also a research effort in fabrication and characterization of potassium $\beta^{\prime \prime}$-alumina for application to a potassium AMTEC, and ongoing effort in design of alternative geometries for AMTEC cells.

Significant progress has been made in electrode performance studies. The Vapor Exposure Test Cell (VETC) has been used to study the effects of high temperature and sodium vapor on new electrode materials, as well as to study the effects of electrode and current collecting materials on each other. Platinum/tungsten alloy thin film electrodes have been tested in the VETC with very promising results.

For the Liquid-Metal Magnetohydrodynamic Electric Generator (LMMHD) activity a full set of equations governing fluid dynamic, thermodynamic and electrodynamic processes in the LMMHD generator have been written. This closed set contains 36 equations, formulas, fluid properties and assumptions. One of two main assumptions is that heat transfer between the liquid metal and the gas in the LMMHD generator is perfect, i.e., that the liquid metal and gas have the same temperature at each individual cross-section. This temperature does change but only a few degrees as the two-phase flow moves along the generator. It is known from previous experimental evidence that the above assumption is a very good approximation of reality.

The second important assumption is that there is no velocity slip between the gas and liquid metal. The air-water mixing experiments, reported earlier in the task, have 
shown that very low velocity slip can be achieved if the mixer is properly designed and surface activity is used to prevent coalescence of bubbles. The LMMHD experiments will use a properly designed mixer and surface active additives, high expansion ratio, and short flow residence time. All of these will help to maintain a very low slip foam flow pattern in the LMMHD generator.

A computer numerical code was written which solves the set of governing equations at one cross-section of the generator and then marches in 110 small steps along the generator. Total current output from the generator is calculated and then load voltage reevaluated and corrected. Following this, with the new load voltage guess, calculations along the generator are repeated until changes in the voltage become sufficiently small. After convergence is indicated the calculations are terminated.

Three different shapes of LMMHD generator have been analyzed. Flow parameters in the nozzle are predicted as well, using the same computer code. Flow conditions at the outlet of the nozzle were used as input parameters at the LMMHD generator inlet for computer predictive calculations.

Typical prediction results show electrical power outputs from the LMMHD generator (which has about a $220 \mathrm{~mm}$ long generating part) in excess of $20 \mathrm{KWe}$. Generator efficiencies are about 71 percent. Velocities all along the nozzle and LMMHD generator are kept below the two-phase sonic velocity. Pressure at the nozzle entrance is 
32.1 bars and it drops to 2.0 bars at the generator exit. The void fraction between the same two locations changes from 0.42 to 0.92 . The total temperature drop is only $3.85 \mathrm{~K}$.

Complete engineering design drawings of the mixer and nozzle for the NaK- $\mathrm{N}_{2}$ blowdown experiments have been developed and submitted to a manufacturing shop for fabrication. Preliminary engineering design of the experimental LMMHD generator has been completed. It utilizes results of the predictive analysis. The generator incorporates a number of pressure taps and "windows" for $\mathrm{x}$-ray measurements of local void fraction profiles.

Construction of the LMMHD blow-down NaK- $\mathrm{N}_{2}$ loop has continued. The assigned location was modified to serve the loop. The magnet with its cooling and control system has been installed. Two sixty gallon, stainless steel tanks were acquired to serve as NaK supply and receiver tanks. The two-phase flow separator has been purchased and installed. Most of the valves and fittings have been acquired. Presently, the installation of the $\mathrm{NaK}$ and $\mathrm{N}_{2}$ piping is in progress. 


\section{A. INTRODUCTION}

A comprehensive introduction to the Direct Conversion Technologies activities appears in Ref. 3. Descriptions of various direct thermal-to-electric conversion systems appear in Refs. 1-5. The systems described are: Alkali Metal Thermal-to-Electric Converter (AMTEC), Two-Phase Liquid Metal MHD (LMMHD) Electric Generator, Thermoelectric, Thermionic, Pyroelectric, Thermoacoustic, Thermoelastic (Nitinol heat engine), Thermophotovoltaic, and a variety of Thermomagnetic concepts. Assessments of these systems have been made and research needs have been identified for systems which, if developed, appear to show promise for energy conservation in the end-use sector. Initially, two systems were selected for exploratory research and advanced development. These are AMTEC and LMMHD. This report presents progress that has been made during CY 1991 on research activities associated with these two systems.

\section{B. OBJECTIVES}

The overall objective of the direct conversion technology task is to develop an experimentally verified technology base for promising direct conversion systems that have potential application for energy conservation in the end-use sectors. Specific objectives are:

1. For the Alkali Metal Thermal-to-Electric Converter demonstrate efficiencies greater than $10 \%$ for a full tube in the Recirculating Test Cell (RTC) and demonstrate electrode stability and performance in long term, high temperature tests in the Vapor Exposure Cell (VETC). 
2. For the Two-Phase Liquid-Metal MHD Electric; (1) develop a computer code to predict performance and assist in the design of an experimental LMMHD generator; (2) design the mixer-nozzle-LMMHD generator assembly; and (3) continue construction of the liquid metal blowdown loop.

\section{RESEARCH ACTIVITIES}

\section{Alkali Metal Thermal-to-Electric Converter (AMTEC)}

\section{a. Thermal Analysis of an AMTEC Cell}

The most recent RTC experiment lasted 850 hours. For approximately $90 \%$ of that period the cell was operated under load with currents ranging from a few milliamperes to 52 amperes. The electromagnetic (EM) pump operated 795 hours during this experiment, with continuous operation of over 300 hours. The major thermal management innovations in this experiment included a heat shield wrapped around the feed-through as well as the heat shield around the electrode and a new heat shield design (two concentric mesh cylinders) which was designed to wet with condensed sodium to make a highly reflective, low emissivity, shield. Other innovations included new feed through and lead wire insulator configurations.

This 850 hour experiment was operated only in sustained mode during its life. The highest efficiency reached was $8.4 \%$, early in life. After the molybdenum electrode had matured, the efficiency was $7.2 \%$. The efficiency was lower than expected because of poor electrode performance and poor thermal performance. Thermal loss was significantly 
greater than expected, $1.7-2.2 \mathrm{~W} / \mathrm{cm}^{2}$, primarily caused by poor reflectivity, and therefore high emissivity, of the condenser. After 360 hours of operation, air leaked into the cell, and performance degraded significantly. However, during periods of constant current operation, thermal performance improved. This improvement is attributed to wetting of the condenser with sodium, which increased the reflectivity, and therefore the emissivity of the condenser. Complete quantitative thermal analysis of this experiment is in progress. The observation that condenser emissivity improves during operation is encouraging as it is clear that cell performance will improve over time, and that potentially harmful events, such as a one time oxygen leak, can be repaired by operation of the cell.

In an earlier RTC experiment that lasted over 200 hours, the electromagnetic pump performed well and was able to keep liquid sodium recirculating as power was drawn. This experiment used a $100 \mathrm{~cm}^{2} \mathrm{RhW}$ electrode and it was found that the use of a heat shield significantly cut radiative loss from the electrode to the condenser. For this experiment, radiative heat loss was cut $10-30 \%$ compared with a previous RTC experiment. This loss was measured by comparing the amount of energy needed to heat the electrode to the same temperature in the two tests. Complete thermal analysis of this experiment is being done, including calculation of condenser emissivity.

A reduction of the heater power by 10 to $30 \%$ was observed by using a cylindrical heat shield compared to no heat shield. More quantitative data comparison is difficult because different length heaters were used, which resulted in variable levels of conductive heat loss. 
A third RTC experiment, using a $120 \mathrm{~cm}^{2}$ Mo electrode, also incorporated a heat shield between the electrode and the condenser. In this experiment, an efficiency of $7.4 \%$ was measured at constant current, and of $11.3 \%$ in dynamic operation (current scanned). This experiment was operated at constant current for over 70 hours. The electromagnetic pump was used continuously during that time. Thermal analysis of this experiment is also being done.

During this experiment, input power was increased during constant current operation to maintain a constant hot zone temperature. The required heat input was greater than expected, as calculated from the sensible and latent heat necessary for the incoming sodium. At currents of 5 to $10 \mathrm{~A}$, the heat input was $200 \%$ greater than the expected value, but at 29 and $42 \mathrm{~A}$, the heat input was only 40 to $50 \%$ greater than expected. A full thermal model as described above will help determine if the discrepancy is a result of a changed temperature gradient over the hot zone or if it will be necessary to add thermal conduction and convection losses in the low pressure sodium to the model.

Understanding of the thermal characteristics of an AMTEC cell will require that the emissivity of the electrode be known so the electrode operating temperature may be measured directly. The emissivity of a $\mathrm{Rh}_{2} \mathrm{~W}$ electrode was measured under vacuum by optical pyrometry, comparing the emissivity to standards held under vacuum in a furnace. This measurement gave a value for the emissivity of 0.7 . The emissivity will be measured again in another apparatus which is now being built. The new apparatus will be used in 
two configurations. One will allow comparison of the temperature of the desired electrode material with standards and simultaneous measurement of the temperature with thermocouples, under vacuum. The second will be used to measure the electrode operating temperature.

Complete analysis of thermal characteristics of the RTC system requires a model with distributed heat input. Such a model is under development (see Appendix B). The simple model now used over-estimates conductive losses. This overestimation results in underestimation of the radiation losses (calculated as the difference between the total heat in and the conductive loss), as well as the condenser emissivities.

\section{b. Electrode Life and Performance Studies and Modeling}

An experiment which lasted 1000 hours in the Recirculating Electrode Test Cell was started in December, 1990 and completed early this year. In that experiment, six $5 \mathrm{~cm}^{2}$ electrodes were deposited on a $\beta$ "-alumina tube. Four of those six electrodes had previously had grid patterns made of molybdenum metal lines $250 \mu \mathrm{m}$ wide in $6 \mathrm{~mm}_{2}$ squares sputter deposited directly on the $\beta^{\prime \prime}$-alumina surface. The electrodes were then contacted with Mo mesh and wires. After the initial 100 hour maturation period, electrodes with grids consistently produced greater power than electrodes without grids. Electrodes with grids performed $20-30 \%$ better than electrodes without grids.

A long term ( $>1300$ hours) experiment in the Vapor Exposure Test Cell (VETC) has 
been run to test the performance of platinum/tungsten alloy electrodes with and without molybdenum current collecting grids deposited by photolytic chemical vapor deposition (photo-CVD). This experiment has shown that in the VETC configuration $\mathrm{Pt}_{4} \mathrm{~W}$ electrodes are superior to $\mathrm{Rh}_{2} \mathrm{~W}$ electrodes and that electrodes with photodeposited grids perform 10 $20 \%$ better than those without grids.

A second VETC experiment with PtW electrodes is now underway. This experiment compares the performance of four compositions of $\mathrm{PtW}$ alloy thin film electrodes $\left(\mathrm{Pt}_{2} \mathrm{~W}\right.$, $\left.\mathrm{Pt}_{3} \mathrm{~W}, \mathrm{Pt}_{4} \mathrm{~W}, \mathrm{Pt}_{5} \mathrm{~W}\right)$ in order to determine the best performing composition.

Both ETC and VETC experimental data are analyzed for performance parameters such as exchange current, morphology factor, electrode resistance and power production. Models to extract kinetic and transport information from VETC data have been developed, and are used to compare electrodes with grids to those without. In addition, a model for correlation of electrode morphology with electrochemical data has been developed.

\section{c. Alternative AMTEC Systems}

Potassium AMTECs were proposed last year, and work continues in this field. The sodium in $\mathrm{Na}-\beta "$-alumina was exchanged for potassium and the conductivity of the ceramic measured in the VETC in potassium atmosphere with Mo electrodes. The results of these measurements show the possibility of building an AMTEC using potassium as the working fluid, which will allow operation at lower temperatures than with sodium. 


\section{TWO-PHASE LIQUID-METAL MHD ELECTRICAL GENERATOR (LMMHD)}

\section{a. Computer Prediction Code}

In order to be able to design an appropriate shape of the LMMHD generator a computer code based on the full set of equations governing fluid dynamic, thermodynamic and electrodynamic processes in a LMMHD generator and in a two-phase nozzle has been developed. The code contains 36 equations, formulas, fluid properties and assumptions. The full set of equations is given in the paper in Appendix D.

One of two main assumptions is that heat transfer between the liquid metal and the gas in the LMMHD generator is perfect, i.e., the liquid metal and the gas have the same temperature across each cross-section and the temperature of the two-phase mixture changes only a few degrees as the flow moves along the generator. It is known from previous experimental evidence that the above assumption is a very good approximation of reality.

The second important assumption is that there is no velocity slip between the gas and the liquid metal. Our air-water mixing experiments (Ref. 6) have shown that very low velocity slip can be achieved if the mixer is properly designed and surface activity is used to prevent coalescence of bubbles, i.e., a proper two-phase flow pattern is maintained. Our LMMHD experiments will use a properly designed mixer and surface active additives, high expansion ratio, and short flow residence time. All of these will help to maintain a very low slip foam flow pattern in the LMMHD generator. 
Additional assumptions are that the flow is steady and one-dimensional and that there is no heat transfer with the surroundings (adiabatic conditions). These assumptions simplify equations considerably.

A flow chart outlining the numerical procedure is given in the paper, Appendix D. Briefly, the procedure consists of first assuming a voltage drop across the electrodes. Then for given inlet flow conditions of the LMMHD generator the computer numerical code solves the set of governing equations at the inlet cross-section of the generator and marches in the same way for 110 small steps along the generator. Next, the total current output from the generator is calculated and then the load voltage is reevaluated based on the outer electrical load resistance. Following this, with the newly assumed load voltage, the calculations along the generator are repeated. This iterative process is repeated until differences in the voltage become sufficiently small. This indicates convergence and the calculations are terminated.

Three different shapes of a LMMHD generator have been analyzed. In all of these the distance between the insulating walls increases linearly from $5 \mathrm{~mm}$ at the inlet to 10 $\mathrm{mm}$ at the outlet. The distance between the electrodes increases from $20 \mathrm{~mm}$ at the inlet to $200 \mathrm{~mm}$ at the outlet, but in three different ways. One way is by linear expansion, the second way is by a large circular arc expansion (of radius of $313 \mathrm{~mm}$ ), and the third way is by a small circular arc (of radius of $150 \mathrm{~mm}$ ) at the inlet with a straight line expansion to the outlet. This third shape appears to have the best performance. 
Flow parameters along the nozzle are predicted as well, using the same computer code. Flow conditions at the outlet of the nozzle were used as input parameters at the LMMHD generator inlet for computer predictive calculations.

The prediction results are discussed in detail in the paper in Appendix D. Here results are outlined only briefly. Typical flow rates are $3 \mathrm{~kg} / \mathrm{s}$ for the liquid metal, NaK, and $0.09 \mathrm{~kg} / \mathrm{s}$ for the gas, $\mathrm{N}_{2}$. Inlet temperature is room temperature. For this particular numerical experiment the pressure at the nozzle inlet is 32.1 bars and then it drops to about half (17.04 bars) at the nozzle outlet. Local sonic velocity is calculated as well making sure that the local fluid velocity is at all locations below the local sonic velocity. The pressure along the generator decreases further from 17.04 bars at the inlet to 2.0 bars at the generator outlet. In this way total pressure ratio across the nozzle and the generator is 16 which is substantially larger than in any earlier LMMHD research. This shoul/d help considerably in maintaining a low slip flow pattern. The fluid velocity at the nozzle inlet is quite small, $1.7 \mathrm{~m} / \mathrm{s}$, but it increases to $82 \mathrm{~m} / \mathrm{s}$ at the nozzle outlet. Finally, at the generator outlet this velocity decreases to $21.7 \mathrm{~m} / \mathrm{s}$. In this way the high velocity in the inlet part of the generator, as well as locally higher strength of the magnetic field (Ref. 1) results in a strong magnetic interaction, i.e., locally high rate of production of electrical energy (it is known that power density is proportional to $B^{2}$ and $U^{2}$ ). In this manner the length of the generator is shortened considerably for the same power output. Another important flow parameter is the void fraction which at the nozzle inlet is 0.42 increasing to 0.58 at the nozzle outlet. With a properly designed mixer it should be easy 
to achieve a bubbly flow pattern at a void fraction of 0.42 . At the generator outlet the void fraction is 0.92 . Because of the very short residence time of the two-phase flow in the nozzle and the generator it is anticipated that a low-slip foam-flow pattern at high void fraction will be maintained.

The total electrical power output from the generator (with a length of the generating section of only $200 \mathrm{~mm}$ ) is predicted to be $21910 \mathrm{~W}$ at the significant generator efficiency of 0.71. However, our present goal is focussed on high exiting void fractions with low slip velocity.

The total predicted current to the external load is 8845 amps. Induced voltage drop across the electrodes is 2.65 volts.

\section{b. Liquid Metal MHD Blowdown Experimental Set-up}

At the present time, engineering design of all components located upstream of the generator has been finalized. A schematic of the test section assembly is shown in Fig. 1. Most of the mixing part of the test section is to be made of commercially available rectangular carbon steel pipe. The outer cross-section of the pipe is $4 \times 4$ inches while the inner section is $3 \times 3$ inches. The inner corners have a radius of $1 / 2$ inch and the wall thickness is $1 / 2$ inch. $\mathrm{NaK}$ is introduced into the rectangular $3 \times 3$ inch pipe via a round 11/2 in. dia., pipe. The NaK flow then encounters a perforated plate which generates uniformly distributed energetic eddies which in turn erase distorting effects on the flow in 
the sudden enlargement at the inlet to the rectangular pipe. The NaK flow then enters a three-inch long honeycomb which eliminates turbulent eddies. The result is a uniform velocity laminar flow.

This flow then enters the mixer section. It contains three gas $\left(\mathrm{N}_{2}\right)$ injection elements which are made of a stainless steel frame and stainless steel porous plates. The plates are three inches wide and ten inches long. The injection elements have twodimensional trailing edge wedges. Gas is introduced into each of the injection elements via two 3/8-in. dia. pipes. These 3/8-in. dia., pipes pass through and are held onto the $4 \times 4$ inch rectangular pipe by swagelok fittings. This way leak tight sealing is ensured both at the $4 \times 4$ inch pipe and at the injection elements. The wedge-shaped trailing edges are held in this proper location by two inserts. These two fiberglass inserts are two-dimensional wedges which are placed on two sides of the $3 \times 3$ in. channel. These two inserts gradually change the inner pipe cross-section from $3 \times 3$ to $3 \times 1.5$ in. Taking into account local dimensions of the trailing edges the net result is a reduction in the available two-phase flow area from $3 \times 1.875$ inches to $3 \times 1.5$ inch. In this way a slight acceleration in a favorable pressure gradient is maintained in this region. This in turn prevents flow separation at the trailing edges which could serve as a source of large gas bubbles that are to be avoided.

The 8-inch long nozzle will be made from a single piece of stainless steel. The inlet dimension is $3 \times 1-1 / 2$ in. and the outlet is $0.787 \times 0.197$ in. The shape of the nozzle is formed by four contracting surfaces which are curved near the nozzle exit in four short 
circular arcs each with a radius of 10 inches. Curvature of the nozzle flow streamlines near the outlet is kept to a minimum in order to minimize the effects of centripetal acceleration on two-phase flow separation. Even if some non-uniformities in the lateral distribution of void fraction were generated by centrifugal forces, the flow should recover its uniformity in the next $1-1 / 2$ in. long straight piece before entering the LMMHD generator region. Once the MHD region is entered the flow will become uniform within a very short distance due to the effectiveness of the MHD forces as long as no breakup in the bubbly two-phase flow pattern occurs. The shape of the nozzle inlet is such that it can be manufactured by an electrodischarge process. Stainless steel was chosen because of its (non)magnetic properties and low electrical conductivity. These properties are needed since the nozzle is adjacent to the MHD generator and will be exposed to some magnetic field. In addition, all inside surfaces of the nozzle and the contact surfaces of the two flanges will be coated with $1 / 16$ in. thick epoxy or some other insulator coating in order to eliminate losses due to current leakage. Manufacturing of all pieces described above has been initiated.

\section{c. LMMHD Generator}

A preliminary engineering design of the LMMHD generator has been made. A decision was made to fabricate the electrodes as well as two compensating plates and two flanges out of aluminum instead of copper. The reason is that aluminum is considerably lighter, less expensive, easier to machine and is much more transparent to $\mathrm{x}$-rays. Aluminum is compatible with $\mathrm{NaK}$, however, it can be eroded by $\mathrm{NaK}$ salts or oxides. To 
avoid this, the inside of the loop will be under $\mathrm{N}_{2}$ cover gas at all times. The outside of the generator will be bare (without insulation) so that any $\mathrm{NaK}$ leak will be detected and cleaned promptly. Two walls of the MHD generator will be made of insulating material such as fiberglass G-10. These walls will be supported by two aluminum flat plates which are often called compensating bars. Their function is to return current which is created within the generator. The returning currents induce a magnetic field which is equal and opposite in sign to the magnetic field induced by the current within the generator. In such a way the induced magnetic field cancels out. The compensating plates also provide structural strength for the generator needed to withstand the internal pressures. The pressure is especially high in the inlet part of the generator. However, the local span of the generator (distance between the electrodes) is quite small making it considerably easier to satisfy the structural criteria. This is also one of the significant advantages of this design of the generator. In the downstream part of the generator, the span is large but the pressures, are much lower, making it again easy to satisfy structural considerations.

The sealing face surfaces of both flanges of the generator will be coated with insulating material to provide electrical insulation and seals. In order to minimize generator end-current electrical losses, both pieces just upstream and downstream of the generator will be coated by an insulating material. These two pieces are the nozzle and transitional exit piece which converts the cross-section from rectangular shape at the generator exit to a round 3-in. dia. pipe. 
In the present design of the generator there are nine "x-ray window pairs" along the generator to measure void fraction profiles across and along the flow. These are machined indentations on the outsides of both electrodes, decreasing electrode thickness in small areas from one inch down to $1 / 8$ inch. The lateral length (in the direction of fluid flow) of the windows is $1 / 4$ in., while their height is larger than the local fluid flow height inside the LMMHD channel (distance between insulating walls). One window pair consists of two indentations, one on each of two electrodes. All pairs are aligned with an $\mathrm{x}$-ray head which will be placed 13 feet away from the generator at its central elevation level. The purpose of the $\mathrm{x}$-ray window pairs is to decrease the amount of "parasitic" attenuation of $x$-rays by the aluminum thickness of the electrodes. The accuracy of the void fraction measurements increases if more of the $x$-ray radiation is attenuated by fluid flow than by the confining walls.

In addition to void fraction measurements, pressure will be measured at eleven locations along the generator via $1 / 16$ in. dia. holes. There are also two pressure taps in the mixer, three in the nozzle and three in the exit piece downstream of the MHD generator.

The exit piece is $11-1 / 2$ inch long. It converts the flow cross-sectional area from rectangular to a 3 in. dia. round pipe. 
One electrode and the compensating plates will be extended on one side outside of the generator for providing connecting surfaces for the buss bars which will take electrical current to the load.

\section{d. Test Facility}

Modification of the experimental test room for the test facility continued in order to satisfy safety requirements. A complete sheet metal wall has been built separating the LMMHD Blowdown Loop from a workshop area. The threshold under the door on this wall is 6 in. high in order to prevent accidental flooding of water to enter the test room. The large blower on the roof of the test room had to be rotated and adapted in order to reverse the ventilating flow in the test area. The magnet has been installed in its proper location. The magnet stand has been raised 22 inches above the floor so that all parts of the test section can be arranged for the flow to be vertically upward. The test section, in addition the LMMHD generator, includes the nozzle, mixer, and $\mathrm{NaK}$ flow conditioning section. The iron core yoke of the magnet, which has a shape of a rectangular frame, has been installed at an angle of 45 degrees with respect of the vertical plane. In this way just enough space is left for the vertical test section to be placed without interfering with the magnet yoke. At the same time there is no interference of the magnet yoke with the $x$ rays, which in the horizontal plane must be transmitted perpendicularly through the MHD channel through the electrodes. The $x$-ray head is placed 13 feet from the MHD generator at its mid-horizontal level. 
The floor pan has more than sufficient capacity to contain all the liquid metal available in the loop. The pan is made of steel with melting temperature above the burning temperature of $\mathrm{NaK}$. This means that in case of a $\mathrm{NaK}$ fire in the pan the $\mathrm{NaK}$ will still be contained by the pan which would not be the case if an aluminum pan were used.

A two-phase flow swirl separator has been selected, purchased and installed in the 3-in. NaK- $\mathrm{N}_{2}$ exit pipe line. Two smaller 60 gallon stainless steel tanks (instead of earlier 300 gallon tanks) have been installed and will be used as the NaK Supply and NaK Receiver Tanks. The tanks are presently rated for pressure of 818 PSIG. Pneumatic flow control needle valves for $\mathrm{NaK}$ and $\mathrm{N}_{2}$ have also been obtained. These and a number of other fittings and valves have been installed in the loop.

The $\mathrm{N}_{2}$ exhaust 3-in. pipe line exits the test room through the roof. On the top of the concrete roof the $\mathrm{N}_{2}$ pipe terminates into a 55-gallon barrel. A stainless steel barrel has been secured for this purpose. A sheet metal cone cover for the barrel has been manufactured.

A 3-inch pneumatic control valve located in the $\mathrm{N}_{2}$ exhaust line has been installed as well. Also installed are, a turbine flow meter for $\mathrm{NaK}$, an orifice flowmeter for $\mathrm{N}_{2}$, and a conduit along the walls of the test room for containing measurement and control cables. 
There are 21 pressure measuring taps on the mixer, nozzle, MHD generator and the exit piece. In order to conserve on the number of pressure transducers, the intention is to use a scanivalve and read all or most of the pressures with only one transducer. All parts of the scanivalve, such as inside seals, are compatible with $\mathrm{NaK}$. 

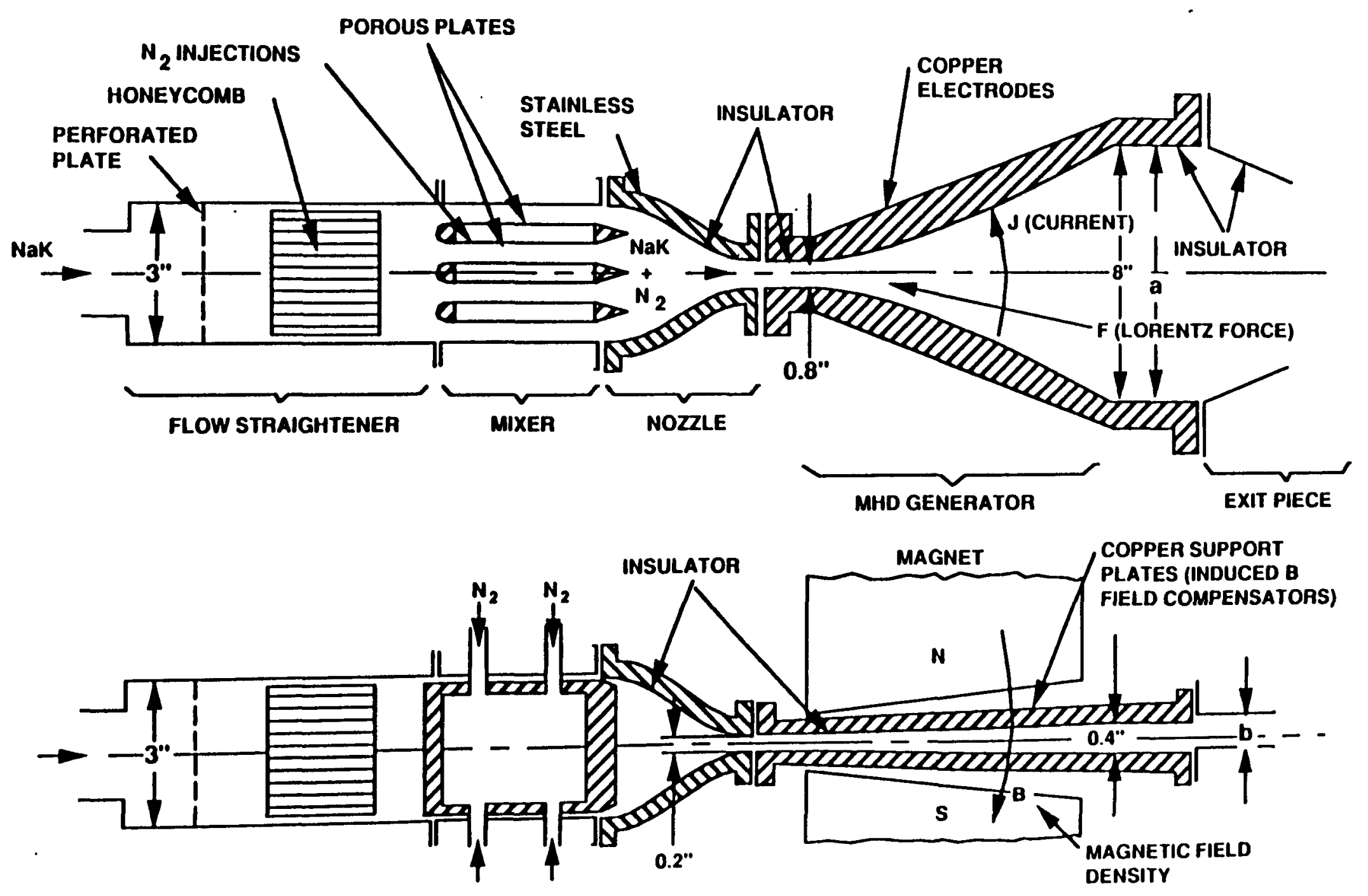

Figure Test Section for the Two-Phase LMMHD Generator. Two Cross-Sectional Views $180^{\circ}$ apart 


\section{REFERENCES}

1. P.F. Massier, M.A. Ryan and G. Fabris, "Direct Conversion Technology Annual Summary Report CY 1990", JPL D-8050, Jet Propulsion Laboratory, Pasadena, California, January 7, 1991.

2. P.F. Massier, C.P. Bankston, R. Williams, M. Underwood, B. Jeffries-Nakamura, and G. Fabris, "ECUT Direct Conversion Technology Annual Summary Report CY 1989," JPL D-6846, Jet Propulsion Laboratory, Pasadena, California, December 4, 1989.

3. P.F. Massier, C.P. Bankston, G. Fabris and L.D. Kirol, "ECUT Direct Conversion Technology Annual Summary Report CY 1988", JPL D-5698, Jet Propulsion Laboratory Pasadena, California, December 1, 1988.

4. P.F. Massier, "ECUT Direct Conversion Technology Annual Summary Report CY 1987", D-4856, Jet Propulsion Laboratory, Pasadena, California, January 7, 1988.

5. P.F. Massier, "ECUT Direct Conversion Technology Project Annual Report CY 1986," JPL D-3707, Jet Propulsion Laboratory, Pasadena, California, January 15, 1987.

6. Fabris, G., Kwack, E., Harstad, K., and Back, L., "Two-Phase Flow Bubbly Mixing for Liquid Metal Magnetohydrodynamic Energy Conversion," 25th Intersociety Energy Conversion Engineering Conference, Reno, NV, Vol. 2, pp. 486-493, August, 1990. 


\section{E. PUBLICATIONS AND PRESENTATIONS}

Two papers discussing AMTEC cell performance, including thermal performance, were presented at the Eighth Symposium on Space Nuclear Power Systems in January, 1991, and will be published in a proceedings volume. These papers, "AMTEC Cell Testing, Optimization of Rhodium/Tungsten Electrodes, and Tests of Other Components" and "Performance Projections for Alternative AMTEC Systems and Devices", appear in Appendix A.

A paper discussing cell and electrode performance, including thermal data, was presented at the 26th Intersociety Energy Conversion Engineering Conference and was published in a proceedings volume. This paper, "Advances in High Temperature Components for AMTEC", also appears in Appendix A.

A paper discussing a distributed elements thermal model for analysis of AMTEC cells will be presented at the Ninth Symposium on Space Nuclear Power Systems, to be held in January, 1992. This paper, "Thermal Modelling of an AMTEC Recirculating Cell" appears in Appendix B.

Other papers and presentations made by members of the AMTEC team in 1991, including three New Technology Reports, which do not specifically refer to thermal analysis are listed in Appendix C. 
A paper titled "Prediction of Performance of Two-Phase Flow Nozzle and Liquid Metal Magnetohydrodynamic (LMMHD) Generator for No Slip Condition" will be presented at the 1992 Intersociety Energy Conversion Engineering Conference (IECEC) to be held in San Diego, California. This paper will also be submitted for publication in the Journal of Energy Research. The paper appears in Appendix D.

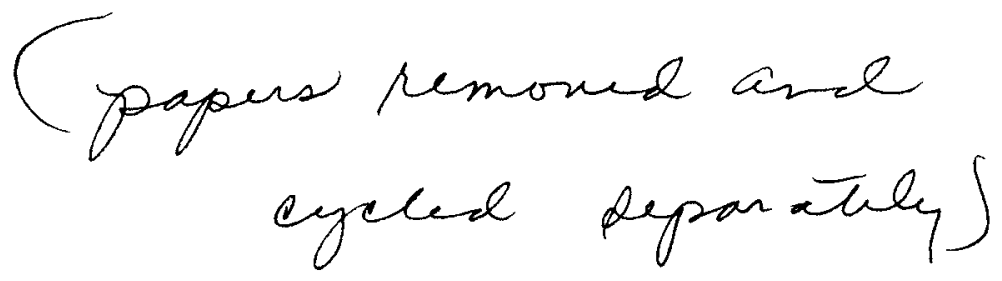

26 